\title{
Experimental Analysis of Micro-CHP System Based on Gas Engine
}

\author{
Ren Teng ${ }^{1, \text { a }}$, Zhou Xiang ${ }^{2, b}$, Xu Weiqing ${ }^{3, \mathrm{c}}$, Cai Maolin ${ }^{4, \mathrm{~d}}$, Shi Yan ${ }^{5, \mathrm{e}}$, \\ ${ }_{1,2,3,4}$ School of Automation Science and Electrical Engineering, Beihang University, Beijing, 100191, \\ CHINA \\ a'Ren_Teng@126.com, bzhouxiang071028@163.com, 'weiqing.xu@buaa.edu.cn, dcaimaolin@bua \\ a.edu.cn, eshiyan@buaa.edu.cn
}

Keywords: micro, CHP, gas engine

Abstract.

This paper studied micro Combined Heat and Power(CHP) system. Generating and waste heat recovery system based on gas engine are set up. Generation and waste heat recovery effects are tested and the results indicate that the system is practicable. Generating efficiency increases as the load rise, while waste heat recovery efficiency goes down.

\section{Introduction}

Nowadays, energy problems has become more severe than ever. World economy and heavy industry rely on fossil fuel to a great extent such as coal, petroleum and natural gas. These non-renewable energy is depleting, and the price of which fluctuates as influenced by the world political situation. Moreover, such fossil energy can make gas or liquid pollution when releasing energy [1]. To solve the problem, we should not only develop new energy, but also improve energy efficiency. Decentralized energy resources(DER) lead to a new orientation for energy problem transformation. Decentralized energy is a new kind of generating system built in or around local users, which can generate electricity and other forms of energy and satisfy local users in top-priority [2].

\subsection{Classification of CHP system}

CHP is a form of DER. CHP means electricity and thermal energy can be obtained simultaneously when utilizing primary energy. A typical CHP system consists of five basic elements: the prime mover, electricity generator, heat recovery system, thermally activated equipment and the management and control system [3]. In China, CHP is widely used in large scale heat power plant, enhancing primary energy utilization [4]. Troditional CHP is mainly applied on large-scale centralized power plants or large industries. With DER developing, some small CHP system appears. However, the development of household micro-CHP falls far behind the world. Japan and Sweden has make great breakthrough on micro-CHP products. Comparing with traditional electricity and heat supply by centralized power and boiler, micro-CHP system used in urban area can improve prime energy efficiency and lower greenhouse gas emission [5]. CHP system can be classified into four categories according scale, shown in Table 1.

Table 1 Classification of CHP

\begin{tabular}{|c|c|c|}
\hline Category & Capacity & Application \\
\hline MicroCHP system & $<20 \mathrm{kw}$ & rare \\
\hline $\begin{array}{l}\text { Small-scale CHP } \\
\text { system }\end{array}$ & 20kw-1MW & $\begin{array}{c}\text { Retail store, } \\
\text { supermarket, building }\end{array}$ \\
\hline $\begin{array}{c}\text { Middle-scale CHP } \\
\text { system }\end{array}$ & 1-10MW & $\begin{array}{c}\text { Industry, no cooling } \\
\text { demand }\end{array}$ \\
\hline $\begin{array}{l}\text { Large-scal CHP } \\
\text { system }\end{array}$ & $>10 \mathrm{MW}$ & Heavy industry \\
\hline
\end{tabular}


Currently, study for CHP above 20kw is mature, while for under 20kw, there is few research. Once power system failures, it will bring massive inconvenience and economic losses. Developing micro CHP technology can release power grid pressure. Therefore, micro CHP can reduce ecomonic losses caused by power failure as emergency power supply.

\subsection{Micro-CHP system}

With the improvement of living standards, demand for hot water is increasing [6]. In troditional heating supply system, natural gas is burnt directly to satisfy the household demand of heat. In CHP system, natural gas is firstly used to produce high grade electricity energy, and waste heat is recovered to heat water. In this way energy is step utilized and the whole energy efficiency is enhanced [7].

In micro-CHP system, natural gas is burnt to drive prime mover to make generator generate electricity and the waste heat is recovered to heat water for household. The micro CHP system is shown in Figure 1.

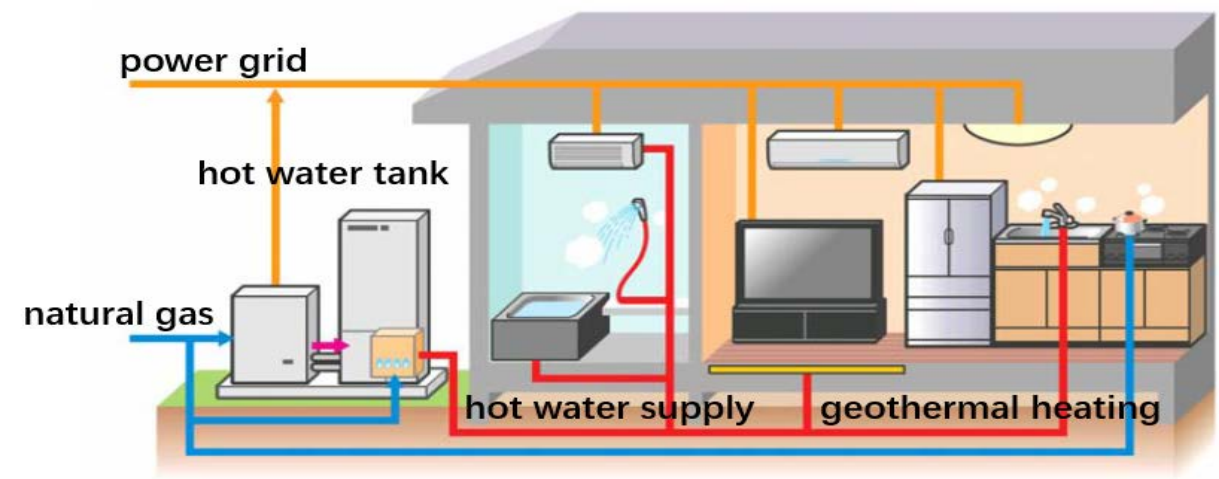

Figure 1 Micro CHP system

\section{Experimental Approach}

\subsection{Model Machine Composition}

The micro-CHP experimental prototype consists of five elements: engine, electricity generator, heat exchanger, water tank and resistance box. The engine drives the electricity generator, and the resistance box can reflect electricity consumption. Water is heated in the heat exchanger by the exhaust gas with high temperature. Therefore, it simulates the situation that Micro-CHP system used in household. The prime mover is motorcycle engine, which is a single cylinder engine of four-stroke. It should be adapted to gas engine. The electricity generator is selected according to the power, which should match the engine power. Thermal recovery system and the water tank are also designed. The micro-CHP prototype is shown in Figure 2. 


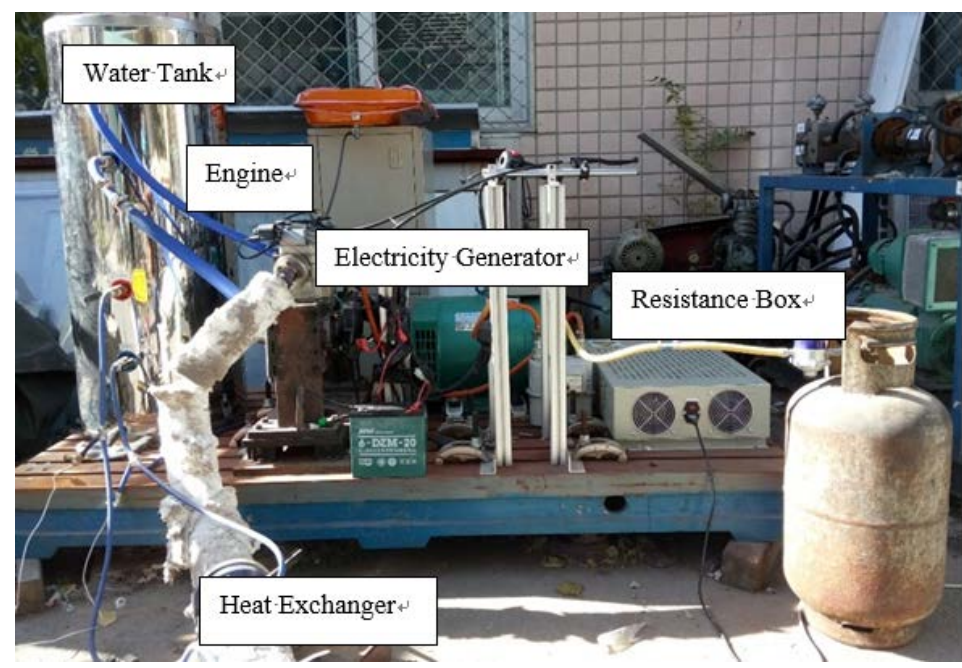

Figure 2 Micro-CHP model machine

\subsection{Engine and Gas Adaption}

Currently, the cooling method of small-scale gas engine is air-cooling, and the waste heat of cylinder body is diffused to the air. Water-cooled engine can take advantage of such thermal energy by jacket water cycle. While the water-cooled engine has large power and high price, and not suit for micro-CHP system. From economic considerations, adapt the miniature fuel internal combustion engine with Oil to Gas technology, which is mature nowadays. The original engine is four-stroke water-cooled motorcycle engine with single cylinder.

Gas is released from the bottle and decompressed through pressure reducing valve. The decompressed gas comes into the vaporizer to modify the pressure. Then, mixed with air in the mixer outside the engine. The gas mixture goes into the engine through inlet passage and combust. The gas distribution system is shown in Figure 3.

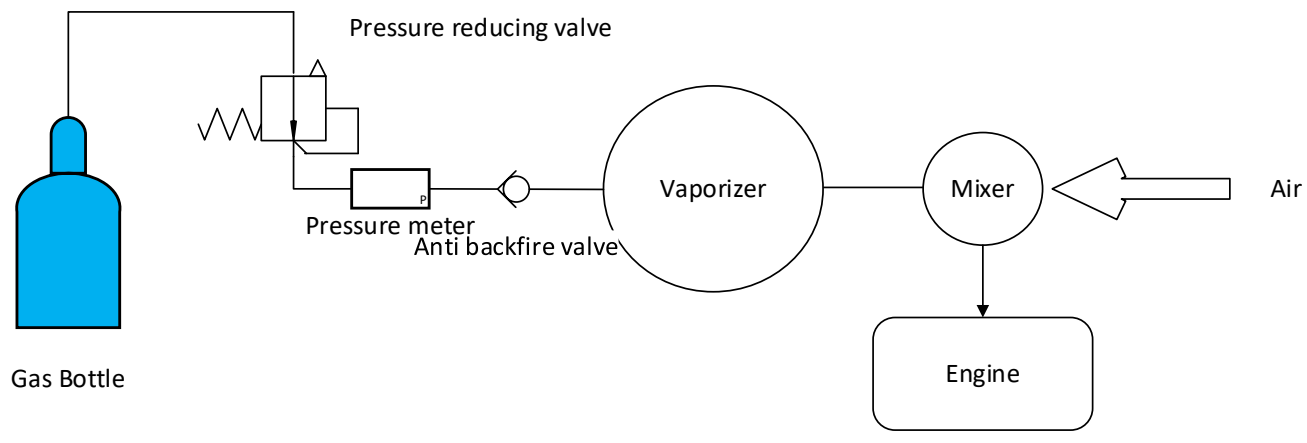

Figure 3 Gas distribution system

\subsection{Design and Test of Generation and Waste Heat Recovery}

Considering reliability and economic factors, in this work we choose single-phase AC synchronous generator. The generation power should also match the engine power, therefore the rated power and speed of the generator are $10 \mathrm{kw}$ and $1500 \mathrm{r} / \mathrm{min}$.

The recycled heat comes from two parts, which are jacket water and waste heat of exhaust. Two water cycles accomplish the heat transfer. There is a circulating pump in the water-cooled engine that can make the jacket water circulation. To utilize the waste heat of the exhaust, a spiral tube heat exchanger is suitable for this system in view of maintenance and economic factors. The waste heat recovery system is shown in Figure 4. 


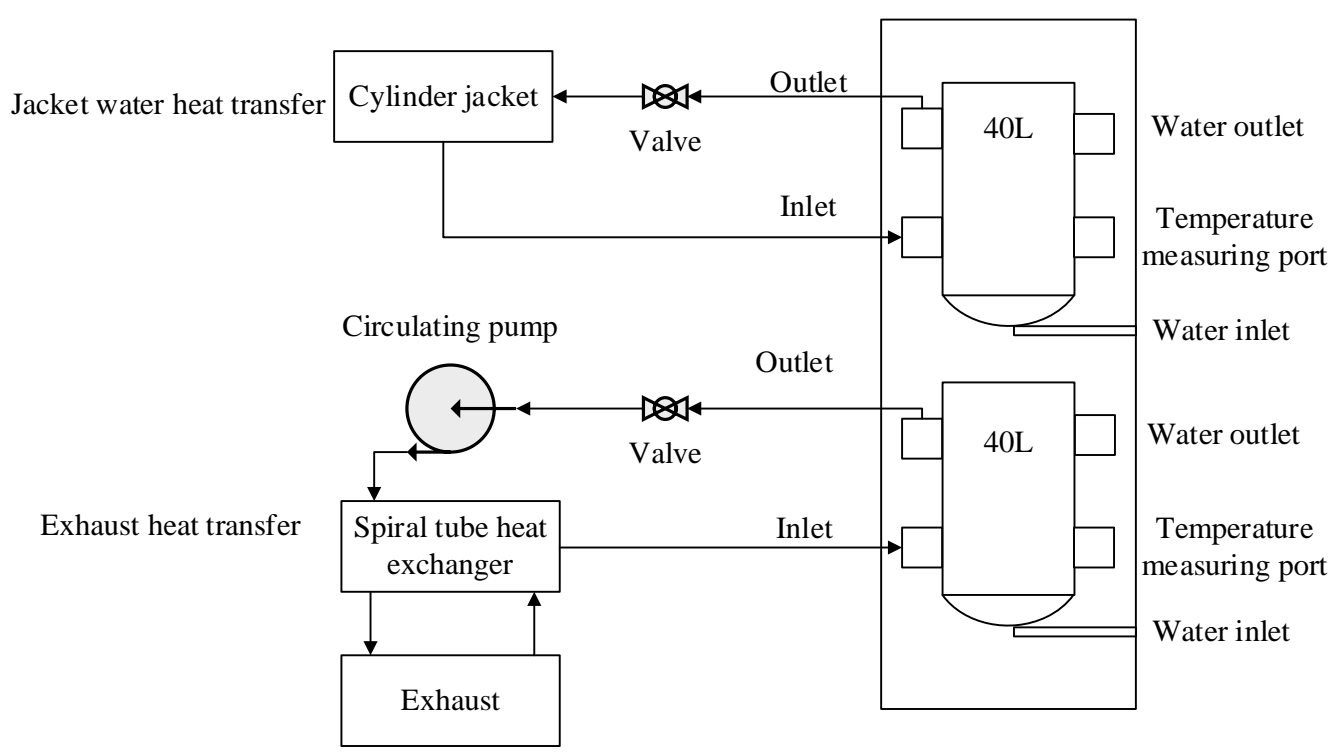

Figure 4 Waste heat recovery system

\section{Experimental Results and Analysis}

We measure the generating and thermal-recovery capacity under different load by $0.1 \mathrm{kw}, 0.5 \mathrm{kw}$, $1.5 \mathrm{kw}$ and $2.0 \mathrm{kw}$. Each experiment time is $5 \mathrm{~min}$, and the water flow rate is $5 \mathrm{~L} / \mathrm{min}$.

\subsection{Generating Efficiency}

The generator speed should stabilize at $1500 \mathrm{r} / \mathrm{min}$ to generate stable alternating current of $220 \mathrm{~V}$. The relation of generated current and load is shown in Figure 5. It can be concluded that the generated current increase in accordance with load.

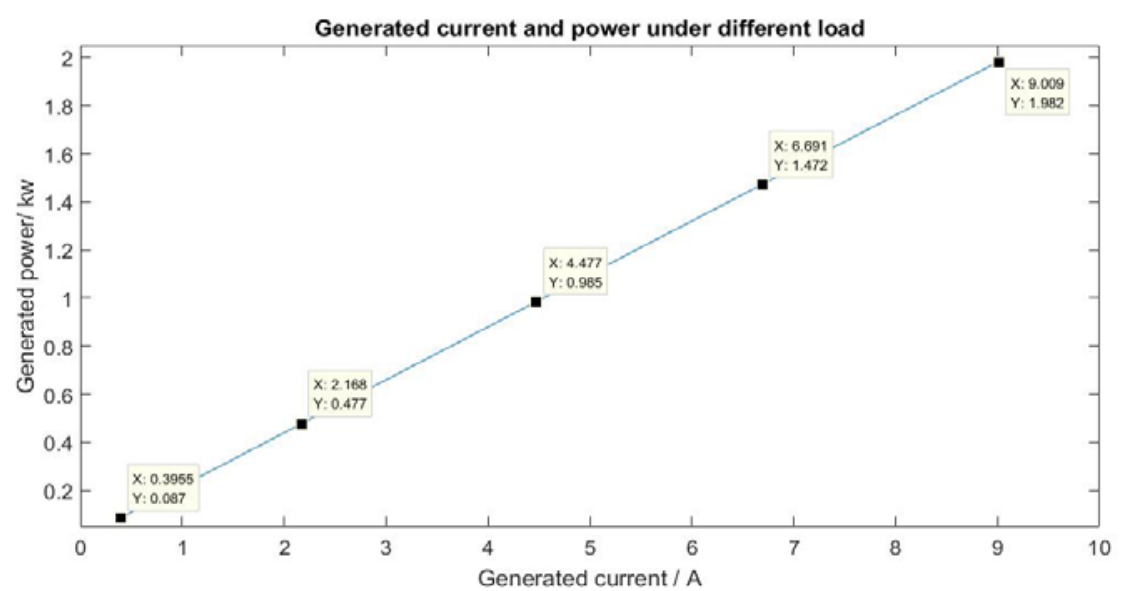

Figure 5 Generated current and power under different load

\subsection{Exhaust Waste Heat Recovery Efficiency}

To obtain the amount of recovery heat, water temperature in the input and output of the heat exchanger should be measured. The relation of water temperature and time is shown in Table 2.

Table 2 Relation of water temperature in heat exchanger and time under different load

\begin{tabular}{cccccc}
\hline Power $/ \mathrm{kw}$ & 0.1 & 0.5 & 1.0 & 1.5 & 2.0 \\
\hline Begin(in, out) $/{ }^{\circ} \mathrm{C}$ & $18.16,18.16$ & $18.74,18.74$ & $18.42,18.42$ & $18.13,18.13$ & $18.81,18.81$ \\
End(in, out) $/{ }^{\circ} \mathrm{C}$ & $27.68,47.65$ & $29.02,51$ & $28.93,52.91$ & $28.82,53.77$ & $29.9,55.9$ \\
\hline
\end{tabular}


From Table 2 we can conclude that water temperature increase both in the input and output of the heat exchanger, and temperature difference also increase with time. It indicates that the increase of heat exchange time can enhance heat exchange effect. Temperature difference also rises as load increasing. Engine power increases with load and emits more exhaust gas and thermal energy, which make heat exchanger absorb more amount of heat, therefore the water temperature difference increase.

\subsection{Jacket Water Waste Heat Recovery Efficiency}

The trend of jacket water temperature varies among time is shown in Table 3. From Table 3 we can conclude that water temperature increase both in the input and output of the jacket, and temperature difference also increase with time. Temperature difference also rises as load increasing.

Table 3 Relation of jacket water temperature and time under different load

\begin{tabular}{cccccc}
\hline Power $/ \mathrm{kw}$ & 0.1 & 0.5 & 1.0 & 1.5 & 2.0 \\
\hline Begin(in, out) $/{ }^{\circ} \mathrm{C}$ & $18.1,18.1$ & $18.71,18.71$ & $18.4,18.4$ & $17.6,17.6$ & $18.79,18.79$ \\
End(in, out) $/{ }^{\circ} \mathrm{C}$ & $25.42,38.77$ & $26.58,41.95$ & $26.68,43.35$ & $26.78,44.91$ & $27.65,47.6$ \\
\hline
\end{tabular}

\section{Summary}

Aiming at household micro-CHP system, we adapt fuel engine to gas engine and set up a model machine and do some tests. The model machine can generated electricity and heat simutaneously, and test results verify the micro-CHP system is practicable. Through tests, we obtained generating and heat recovery efficiency under different load. The results indicate that the more generating power, the more generating and the less thermal recovery efficiency. The whole efficiency of electricity and thermal varies little. When generating power is $2 \mathrm{kw}$, the micro-CHP system generating efficiency is $10.84 \%$, jacket water and exhaust gas thermal efficiency is $20.22 \%$ and 29.53 respectively, the gross thermal efficency is $49.75 \%$, and the overall electricity as well as thermal efficiency is $60.59 \%$.

\section{References}

[1] R. Gheith, H. Hachem, F. Aloui, S. Ben Nasrallah. Experimental and theoretical investigation of Stirling engine heater: Parametrical optimization [J]. Energy Conversion and Management Vol. 105 (2015):285-293.

[2] Wu Dawei, Wang Ruzhu. Definition of distributed energy resources and discussion on its relationship with CCHP [J]. Refrigeration and Air-Conditioning 2005, 5(5).

[3] D.W. Wu, R.Z. Wang, Combined cooling, heating and power: A review [J]. Progress in Energy and Combustion Science 32(2006): 459-495.

[4] Wang Zhenming. Analysis of CHP development in China [J]. Thermoelectric technology 2(2011).

[5] L. Mongibello, N. Bianco, M. Caliano, G. Graditi. Assessment of pollutants emission of two residential micro-CHP systems [J]. 2015 International Conference on Clean Electrical Power(ICCEP): 290-296.

[6] Tian yajie, Liu rong. Market survey and analysis of gas water heaters in Beijing [J]. Gas \& Heat. 2012(5).

[7] Xu Nai-qiang, LEI Li-chang. Combined heat and power generation of Natural gas [J]. Power supply technologies and applications. 2003(10). 